\title{
IMPORTÂNCIA DO PROGRAMA DE PAGAMENTO POR QUALIDADE NA MICROBIOLÓGICA DO LEITE NA REGIÃO DE SÃO LUIS DE MONTES BELOS, ESTADO DE GOIÁS
}

\author{
IMPORTANCE OF THE QUALITY PAYMENT PROGRAM IN MICROBIOLOGICAL \\ MILK QUALITY IN SÃO LUIS DE MONTES BELOS, STATE OF GOIÁS
}

\author{
C. E. G. AGUILAR ${ }^{1}$, A. M. C. VIDAL ${ }^{2}$, G. A. M. $\operatorname{ROSSI}^{3}$, L. F. RIBEIRO ${ }^{4}$
}

\begin{abstract}
RESUMO
O objetivo do presente trabalho é demonstrar a importância dos programas de pagamento por qualidade (PPQ) de leite na melhoria a campo do produto. O presente estudo analisa os dados desde 2008, ano da implantação do mencionado programa por um laticínio na região de São Luís de Montes Belos, Estado de Goiás, até quatro anos posteriores da mesma, Além da CBT, o PPQ bonificava outras variáveis, como quantidade de gordura, proteína e Contagem de Células Somáticas (CCS). Foram analisadas, através de amostragem individual de cada produtor pertencente à região, cerca de 4,7 milhões de litros de leite por mês. Tais análises foram realizadas em um dos laboratórios credenciados ao MAPA e ponderadas pelo volume de cada produtor para posterior comparação.No início do ano de implantação do PPQ, a CBT média, ponderada pelo volume dos produtores, era de 2.171.236 UFC/ml. A melhoria da qualidade nos quatro anos que sucederam a implantação do PPQ foi constante. No último mês de acompanhamento, houve redução de $88 \%$ na CBT comparada a inicial, passando a mesma a ser de $251.549 \mathrm{UFC} / \mathrm{ml}$. Para os produtores que já fornecem leite à empresa, o PPQ serve como estímulo de melhoria, além de atrair novos fornecedores que queiram valorizar o leite fornecido por eles. Em contrapartida, produtores que acabam por ter valores descontados pela má qualidade, acabam por migrar para outros laticínios ou ainda abandonar o ramo lácteo. Diante do exposto, demonstra-se a importância dos Programas de Pagamento por Qualidade no setor lácteo, visto que uma melhor remuneração ao produtor de leite colabora para uma diminuição do êxodo rural, além de facilitar o atendimento ás legislações vigentes e fornecer alimentos seguros para que sejam adquiridos por consumidores cada vez mais exigentes.
\end{abstract}

PALAVRAS-CHAVE: CONTAGEM BACTERIANA TOTAL, LATICÍNIOS, MICROBIOLOGIA DE ALIMENTOS

ÁREA TEMÁTICA: Higiene e Inspeção de Produtos de Origem Animal.

\footnotetext{
${ }^{1}$ Pós-graduando (nível doutorado) em Medicina Veterinária, Departamento de Medicina Veterinária Preventiva, Universidade Estadual Paulista, Faculdade de Ciências Agrárias e Veterinárias, Jaboticabal. kadugamero@hotmail.com ${ }^{2}$ Prof $^{a}$. Doutora, Departamento de Medicina Veterinária, Universidade de São Paulo, Faculdade de Zootecnia e Engenharia de Alimentos, Pirassununga. anavidal@usp.br

${ }^{3}$ Pós-graduando (nível doutorado) em Medicina Veterinária, Departamento de Medicina Veterinária Preventiva, Universidade Estadual Paulista, Faculdade de Ciências Agrárias e Veterinárias, Jaboticabal. gabrielrossiveterinario@ hotmail.com

${ }^{4}$ Pós-graduando (nível doutorado) em Medicina Veterinária, Departamento de Medicina Veterinária Preventiva, Universidade Estadual Paulista, Faculdade de Ciências Agrárias e Veterinárias, Jaboticabal. laryssaribeiro84@gmail.com Correio eletrônico do autor responsável: kadugamero@ hotmail.com
} 